\title{
Switching perspectives: Do mineral fluxes determine particulate organic carbon fluxes or vice versa?
}

\author{
Uta Passow \\ Alfred Wegener Institute for Polar and Marine Research, D-27515, Bremerhaven, Germany \\ (upassow@awi-bremerhaven.de)
}

[1] It has recently been postulated that mineral material like biogenic silica frustules or carbonate shells as well as lithogenic dust act as ballast material determining particulate organic carbon (POC) fluxes below $2000 \mathrm{~m}$ in the ocean. However, correlations do not identify cause and effect, and in this commentary it is proposed that on the contrary, POC fluxes determine fluxes of this mineral material. I suggest that during sedimentation marine snow originating from biological activity in the surface layer collect small, non-sinking mineral particles of biogenic and lithogenic origin until its carrying capacity is reached.

Components: 2673 words, 1 figure, 1 table.

Keywords: Ballast minerals; carbon flux; mineral flux.

Index Terms: 1615 Global Change: Biogeochemical processes; 4806 Oceanography: Biological and Chemical: Carbon cycling; 4815 Oceanography: Biological and Chemical: Ecosystems, structure and dynamics.

Received 2 December 2003; Revised 2 February 2004; Accepted 2 March 2004; Published 6 April 2004.

Passow, U. (2004), Switching perspectives: Do mineral fluxes determine particulate organic carbon fluxes or vice versa?, Geochem. Geophys. Geosyst., 5, Q04002, doi:10.1029/2003GC000670.

[2] If we are to understand the global carbon cycle and evaluate impacts of rising atmospheric $\mathrm{CO}_{2}$ concentrations, fluxes of particulate organic carbon (POC) from the surface ocean to the ocean interior need to be understood and predictable on a global scale. In the past POC fluxes at depth have been fitted to an empirical power law relationship based on POC fluxes out of the surface layer [Martin et al., 1987]. However, the necessary parameters vary with geographical area, season and habitat, greatly reducing the predictive power of this relationship.

[3] Recently Armstrong and colleagues have introduced the idea that fluxes of mineral material (silica frustules, carbonate shells and dust) rather than shallow water POC fluxes determine deep POC fluxes [Armstrong et al., 2002]. Empirical observations suggest, that below $1000 \mathrm{~m}$ depth at different geographical locations POC fluxes make up a fairly constant $3-7 \%$ of dry weight fluxes, although absolute POC fluxes vary by more than an order of magnitude. In a detailed analysis Klaas and Archer [Klaas and Archer, 2002] confirm and refine the hypothesis put forward by Armstrong and colleagues, demonstrating that the carrying capacity for POC differs for the different inorganic particle types. The carrying capacity of calcium carbonate is around $7 \%$, the carrying capacity of opal $\leq 3 \%$ and that of lithogenic material varies more widely between 3 and 7\%. This relationship, if it remains valid, is extremely useful for predictive purposes and modeling, and has set off an animated debate on its consequences for our understanding of the interrelationship between the marine carbon cycle and atmospheric $\mathrm{CO}_{2}$ concentrations. It challenges the "rain-ratio hypothesis" 
[Ridgwell, 2003], which has been proposed as a main mechanism controlling atmospheric $\mathrm{CO}_{2}$ [Archer and Maier-Reimer, 1994], or when combined with the rain-ratio hypothesis may predict a net positive feed back to rising atmospheric $\mathrm{CO}_{2}$ concentrations [Barker et al., 2003]. Additionally, the proposed constant relationship between POC flux and mineral flux raises the intriguing question regarding possible mechanisms responsible for this relationship.

[4] Are there any feasible mechanisms by which the fraction of POC surviving the transit through the water column without degradation is determined by the flux of biogenic and lithogenic minerals to the deep sea? Possibly the fraction of the organic material, which reaches the deep ocean is physically or chemically protected from degradation by its close association with mineral particles [Armstrong et al., 2002]. The relationship between the carrying capacity of each mineral and its density, on the other hand, suggests sinking speeds of aggregates to be involved [Klaas and Archer, 2002]. However, as degradation rates in the deep ocean are thought to be low, a significant reduction of degradation based on increased sinking speeds, when the organic content of aggregates is reduced to the magical $5 \%$ of minerals, is, as Klaas and Archer pointed out, fairly unlikely. Or else, the protected POC may represent the surface coating of organic material on the mineral particles. As soon as this layer is degraded, it would spontaneously be reformed from the large pool of dissolved material. The mineral associated POC would in this case be a function of the surface area and the properties of minerals and may be fairly constant for any one type of material. This would imply that only negligible amounts of the particulate matter originating from the surface, reaches the deep ocean, which contradicts observations of sinking marine snow and of fluff and live cells observed at the seafloor. In the N. Atlantic at least, the sedimentation of the spring bloom contributes significantly to the annual sedimentation signal at depth.

[5] Alternatively, the problem can be looked at from the opposite perspective: does the POC flux determine the flux of biogenic and lithogenic inorganic particles, rather than the other way around? The POC fluxes at depth may, as has been assumed in the past be determined by upper ocean processes, such as production regime, food web structure, remineralization regime. This material sinks to depth predominantly as large $(>0.5 \mathrm{~mm})$ aggregates called marine snow, which settle at velocities of 50 to $200 \mathrm{~m} \mathrm{~d}^{-1}$. Diatom aggregates can efficiently collect and sediment large amounts of fine clay or quartz particles too small to sink individually [Hamm, 2002]. Assuming that the ocean below the mixed layer harbors an excess of mineral particles too small to sediment at significant speeds, any sinking POC-rich marine snow passing through would scavenge such inorganic particles to the carrying capacity of the organic material. The carrying capacity of POC for such particles may well be fairly constant and vary with particle type. Such small mineral particles may include lithogenic material from dust input, as well as biogenic material like coccoliths, calcium carbonate shells and silica frustules and their fragments. The settling velocity of small fragments or individual coccoliths or even coccospheres is so slow $\left(0.1 \mathrm{~m} \mathrm{~d}^{-1}\right)$, that these will not settle significantly except in aggregates or fecal matter [Steinmetz, 1994].

[6] The co-sedimentation of biogenic and lithogenic minerals with POC has been shown to be important locally in areas influenced by run-off. Recalculations of flux data at $500 \mathrm{~m}$ depth, collected during a two-year time series study in the basin of the Santa Barbara Channel [Passow et al., 2001], revealed that the relationship postulated by Klaas and Archer holds for this seasonal data set as well, although the trap was significantly shallower and although inorganic material was clearly dominated by lithogenic particles (Figure 1). POC flux at that station constitutes $5 \%$ of dry weight flux and can be predicted from the biogenic silica, lithogenic silica and calcium carbonate fluxes, with carrying capacities similar to those found by Klaas and Archer (Table 1). The overall statistical relationship held, although microscopical examination revealed that the seasonal sedimentation event of intact foraminifera shells was not associated with a significant sedimentation of POC. At this station, 

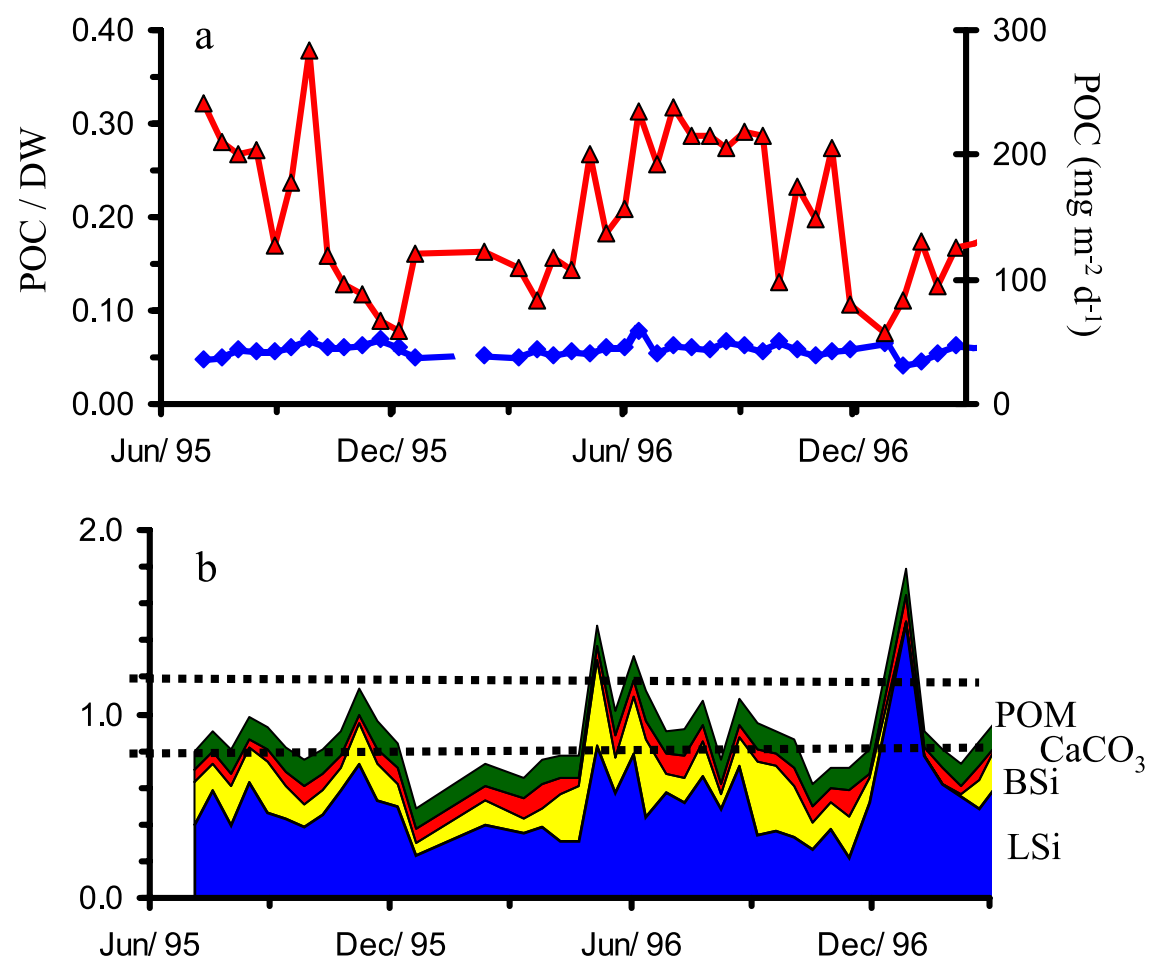

Figure 1. (a) Sedimentation rate of POC (red line, triangles) and relative sedimentation of POC normalized to dry weight (DW) (blue line, diamonds) at $500 \mathrm{~m}$ depth during a 2-year study in the Santa Barbara Channel, from [Passow et al., 2001]. Whereas POC sedimentation rate varied by a factor of five, the ratio between POC and DW fluctuated only slightly around $5 \%$. (b) Relative composition of sinking material normalized to dry weight, assuming a POM to POC ratio of 2.199, and a factor of 60 for the conversion from mol to gram of biogenic and lithogenic silica. This conversion yields only a crude estimate of total weight of lithogenic silica, causing the overall sum to frequently deviate appreciably from 1 . Only days where the sum of $\mathrm{LSi}, \mathrm{BSi}, \mathrm{CaCO} 3$ and $\mathrm{POM}$ was larger $\tan 79 \%$ and smaller than $121 \%$ (dotted black lines) were included in the first run of the multiple correlation analysis of POC fluxes versus mineral fluxes (Table 1, line 1).

the lithogenic material, which resides predominantly between 100 and $300 \mathrm{~m}$ and originates from fluvial input and material resuspended from the slopes of the basin, arrived in traps only in association with large sedimentation events of diatom aggregates or appendicularian houses [Passow et al., 2001].
[7] However, can a similar mechanism be assumed for the open ocean, where fluvial clay input is small, and biogenic minerals presumably dominate mineral particles? McCave [1984] calculated loss of small $(0.5 \mu \mathrm{m})$, non-sinking particles in mid water depths due to coagulation with large $(2-4 \mathrm{~mm})$, fast sinking aggregates. Assuming a coagulation

Table 1. Multiple Correlation Analysis of POC Fluxes Versus Mineral Fluxes ${ }^{\mathrm{a}}$

\begin{tabular}{|c|c|c|c|c|c|}
\hline & $\mathrm{BSi}$ & LSi & $\mathrm{CaCO}_{3}$ & $\mathrm{r}$ & $\mathrm{N}$ \\
\hline LSi measured & $0.079 \pm 0.008$ & $0.042 \pm 0.006$ & $0.164 \pm 0.036$ & 0.976 & 25 \\
\hline LSi calculated & $0.061 \pm 0.010$ & $0.045 \pm 0.005$ & $0.186 \pm 0.038$ & 0.931 & 43 \\
\hline Klaas and Archer, all traps $>1000 \mathrm{~m}$ & $0.025 \pm 0.011$ & $0.035 \pm 0.006$ & $0.094 \pm 0.010$ & 0.962 & 107 \\
\hline
\end{tabular}

\footnotetext{
${ }^{a}$ Line 1 (LSi measured) depicts results using only data where the sum of $\mathrm{LSi}, \mathrm{BSi}, \mathrm{CaCO}_{3}$ and $\mathrm{POM}$ ranged between $80 \%$ and $120 \%$ of dry weight. Line 2 (LSi calculated) depicts results using values of LSi calculated by subtracting BSi, CaCO3 and POM from dry weight, as in Klaas and Archer. Line 3 depicts results from the analysis of "all traps $>1000 \mathrm{~m}$ " presented in Klaas and Archer, Table 1. Small differences in the respective carrying capacities between the seasonal data from the Santa Barbara Channel (SBC) and the globally geographic data by Klaas and Archer may easily be explained by the shallower depth of the sediment traps in the SBC and the dominance of LSi there.
} 
efficiency of unity, a density of small mineral particles of $2.0 \mathrm{~g} \mathrm{~cm}^{-3}$ and that aggregates sink through $2000 \mathrm{~m}$ of water, the sedimentation rate of small particles can be calculated to be around $310^{-3} \mathrm{~g} \mathrm{~m}^{-2}$ $\mathrm{d}^{-1}$. This value is 3 to 4 orders of magnitude smaller than the respective sedimentation rates measured with deep sediment traps (10-20 $\mathrm{g} \mathrm{m}^{-2} \mathrm{~d}^{-1}$ ) [e.g., Antia et al., 2001]. Although all assumptions could be challenged, the weakest point in this calculation lies in the assumptions of particle concentrations, as particle abundance data especially of non-sinking particles at depth is scarce and tedious to generate. McCave's calculations assumed concentrations of $0.02 \mathrm{dm}^{-3}$ and $10^{7} \mathrm{dm}^{-3}$ for marine snow (4$5 \mathrm{~mm})$ and small $(0.5 \mu \mathrm{m})$ particles, respectively. Marine snow concentrations in the NE Atlantic at $300 \mathrm{~m}$ depth varied during a five months period between 0.2 and $10 \mathrm{dm}^{-3}$ [Lampitt et al., 1993], concentrations 1-3 orders of magnitude higher than those assumed by McCave. More important in this context, concentrations of particles between 0.02 and $8 \mu \mathrm{m}$ found in the Gulf Mexico between 600 and $3600 \mathrm{~m}$ depth $\left(5-10 * 10^{9} \mathrm{dm}^{-3}\right)$, [Harris, 1977], suggest that small particles, which have a theoretical residence time of around 100 years if sinking individually [Lambert et al., 1981], may also be 2-3 orders of magnitude more common than assumed by McCave. These small, suspended particles consisted of fragments of coccoliths or diatom frustules, as well as lithogenic material. Estimates of the sedimentation rate of these small mineral particles based on the maximum concentrations cited above would yield sedimentation rates up to $>2$ orders of magnitude higher than those measured by traps.

[8] Correlations do not identify cause and effect. POC flux has been shown to depend - in a complex fashion - on biological processes like new production and food web structure [Rivkin et al., 1996] as well as on aggregation dynamics. Aggregation and composition of aggregates are a function of the presence of extracellular polymers [Avnimelech and Troeger, 1982; Passow et al., 1994], suggesting that a fraction of the POC pool may determine flux rates of both bulk POC and mineral particles. Very little is known about mechanisms determining the size distribution and settling behavior of min- eral particles like calcium carbonate shells, coccoliths or diatom frustules and fragments thereof in the deep ocean. Loss of biogenic frustules and shells depends on complex processes like aggregation/disaggregation or grazing, both of which change the size distribution and thus sinking velocity and dissolution rate of small biogenic particles. Knowledge of the mechanisms determining mutual aggregation between POC and inorganic particles and the effects of mutual aggregation on aggregate sinking velocity is also insufficient (but see Azetsu-Scott and Passow [2004]). Clearly, more, reliable abundance data on the vertical distribution of small, non-sinking particles in the open ocean is needed, before the interaction between inorganic and organic particles in determining particle flux can be understood. If the concentration of such non-sinking inorganic particles below the mixed layer depth is high the question on the causes of such an accumulation would pose itself. Currently our knowledge does not permit an unequivocal allocation of cause and effect and the question if on global scales POC fluxes determine fluxes of biogenic and lithogenic inorganic material or vice versa remains open for debate.

\section{Acknowledgments}

[9] I thank Rob Armstrong and Christine Klaas for their gift of an intriguing scientific puzzle and several colleagues for their comments to this paper.

\section{References}

Antia, A. N., W. Koeve, G. Fischer, T. Blanz, D. SchulzBull, J. Scholten, S. Neuer, K. Kremling, J. Kuss, and R. Peinert (2001), Basin-wide particulate carbon flux in the Atlantic Ocean: Regional export patterns and potential for atmospheric CO2 sequestration, Global Biogeochem. Cycles, 15(4), 845-862.

Archer, D., and E. Maier-Reimer (1994), Effect of deep sea sedimentary calcite preservation on atmospheric $\mathrm{CO} 2$ concentration, Nature, 367, 260-263.

Armstrong, R. A., C. Lee, J. I. Hedges, S. Honjo, and W. G. Stuart (2002), A new mechanistic model for organic carbon fluxes in the ocean based on the quantitative association of POC with ballast minerals, Deep Sea Res. Part II, 49, 219 236.

Avnimelech, Y., and B. Troeger (1982), Mutual flocculation on algae and clay: Evidence and implications, Science, 216, $63-65$. 
Azetsu-Scott, K., and U. Passow (2004), Ascending marine particles: Significance of TEP in the upper ocean, Limnol. Oceanogr., in press.

Barker, S., J. A. Higgins, and H. Elderfield (2003), The future of the carbon cycle: Review, calcification response, ballast and feedback on atmospheric CO2, Philos. Trans. R. Soc. London Ser. A, 361, 1977-1999.

Hamm, C. E. (2002), Interactive aggregation and sedimentation of diatoms and clay-sized lithogenic material, Limnol. Oceanogr., 47(6), 1790-1795.

Harris, J. E. (1977), Characterization of suspended matter in the Gulf of Mexico: II. Particle size analysis of suspended matter from deep water, Deep Sea Res., 24, 1055-1061.

Klaas, C., and D. E. Archer (2002), Association of sinking organic matter with various types of mineral ballast in the deep sea: Implications for the rain ratio, Global Biochem. Cycles, 16(4), 1116, doi:10.1029/2001GB001765.

Lambert, C. E., C. Jehanno, N. Silverberg, J. C. Brun-Cottan, and R. Chesselet (1981), Log-normal distribution of suspended particles in the open ocean, J. Mar. Res., 39, 77-98.

Lampitt, R. S., W. R. Hillier, and P. G. Challenor (1993), Seasonal and diel variation in the open ocean concentration of marine snow aggregates, Nature, 362, 737-739.
Martin, J. H., G. A. Knauer, D. M. Karl, and W. W. Broenkow (1987), Vertex: Carbon cycling in the northeast Pacific, Deep Sea Res., 34, 267-285.

McCave, I. N. (1984), Size spectra and aggregation of suspended particles in the deep ocean, Deep Sea Res. Part I, 31, 329-352.

Passow, U., A. L. Alldredge, and B. E. Logan (1994), The role of particulate carbohydrate exudates in the flocculation of diatom blooms, Dee Sea Res. Part I, 41, 335-357.

Passow, U., R. F. Shipe, A. Murray, D. K. Pak, M. A. Brzezinski, and A. L. Alldredge (2001), Origin of transparent exopolymer particles (TEP) and their role in the sedimentation of particulate matter, Cont. Shelf Res., 21, 327-346.

Ridgwell, A. J. (2003), An end to the rain ratio reign, Geochem. Geophys. Geosyst., 4(6), 1051, doi:10.1029/ $2003 \mathrm{GC} 000512$.

Rivkin, R. B., et al. (1996), Vertical flux of biogenic carbon in the ocean: Is there food web control?, Science, 272(5265), $1163-1166$.

Steinmetz, J. C. (1994), Sedimentation of coccolithophores, in Coccolithophores, edited by A. Winter and W. Siesser, pp. 179-197, Cambridge Univ. Press, New York. 